This is an electronic reprint of the original article. This reprint may differ from the original in pagination and typographic detail.

Author(s): Salonen, Ville; Karjaluoto, Heikki

Title: Web Personalization : The State of the Art and Future Avenues for Research and Practice

Year: $\quad 2016$

Version:

Please cite the original version:

Salonen, V., \& Karjaluoto, H. (2016). Web Personalization : The State of the Art and Future Avenues for Research and Practice. Telematics and Informatics, 33(4), 10881104. https://doi.org/10.1016/j.tele.2016.03.004

All material supplied via JYX is protected by copyright and other intellectual property rights, and duplication or sale of all or part of any of the repository collections is not permitted, except that material may be duplicated by you for your research use or educational purposes in electronic or print form. You must obtain permission for any other use. Electronic or print copies may not be offered, whether for sale or otherwise to anyone who is not an authorised user. 


\section{Web Personalization: The State of the Art and Future Avenues for}

\section{Research and Practice}

\section{Abstract}

Although web personalization has been examined by earlier literature reviews, an updated analysis of recent advances in the field is needed. The authors extend prior reviews of web personalization by discussing current areas of interest, research gaps and future directions. A literature review of the top 20 marketing and information systems journals published during the period of 2005 - 2015 (May) shows active research output and the domination of IS publications. The examined research addresses three categories: user-specific aspects, implementation, and theoretical foundations. We then analyze a total of ten themes: six on topics concerning user-specific aspects and implementation that stem from the dataset and four on theoretical foundations that are predetermined and reflected upon using the dataset. Both theme-specific and general future research suggestions are discussed. Advanced contextualization is suggested as the primary area suitable for future research and building evidence for attaining business goals as a secondary topic. Finally, we propose a conceptualization of interpolated web personalization to be tested as a potential complement to current (extrapolated) approaches.

Keywords: web personalization, literature review, recommender systems, user-specific aspects, implementation, contextual information 


\section{Introduction}

The conditions are excellent for web personalization to prosper. Through the digitalization of everyday life, an increasing number of datapoints are becoming available, revealing ever more detailed aspects of consumer preferences. Recent technological advances enable procedures that create comprehensive, personalized experiences on the web using the insights gained from the collection of datapoints. Even the available computational power, which was deemed a potential threat to the advancement of web personalization (Montgomery \& Smith 2009), has not hampered the field. Consequently, web personalization has matured quickly, and the field is on the rise (Sunikka \& Bragge 2012).

The potential for impact from personalization is considerable. Personalization is generally assumed to be the most effective tool for achieving business success online (e.g., Cao \& Li 2007). Kalaignanam, Kushwaha, and Varadarajan (2008) consider personalization to be a major driver of marketing efficiency. However, the effectiveness of personalization is a contested issue, as results in both online (e.g., Shen \& Ball 2009; Zhang 2011) and offline (McCoy \& Hargie 2007) find little support for it. This disparity creates ambiguity around the field. As the field progresses, there are a host of important topics that currently lack clarity around where the field of web personalization stands and where it is headed.

Prior general literature reviews (Kabassi 2010; Montgomery \& Smith 2009; Sunikka \& Bragge 2012; Tuzhilin 2009; Vesanen and Raulas, 2006) have been instrumental in clarifying the state of the art and producing guidelines for future research. However, fast-paced changes in the field call for an updated review. Importantly, more specific review papers have surfaced recently focused on recommender systems (Lu et al. 2015) and personalization techniques (Gao, Liu \& Wu 2010). Although these specific reviews are valuable for these research 
streams, they are unable to take a more comprehensive view of the field of web personalization. Consequently, timely insights into the direction of the field are lacking. These include both specific topics such as current research interests as well as more general topics such as terminology, methodology, and the interplay of disciplines for contribution.

This paper contributes to the web personalization literature in two primary ways. First, we identify current research topics and streams that help to clarify how the field of web personalization has evolved in the past ten years and where the field stands today. Second, we offer insights into the most notable research gaps identified in the literature and, on this basis, identify important future research directions. The outlined potential future directions will facilitate in generating a meaningful research agenda for the field. We distinguish and discuss ten themes for further research. Six of the themes addressing user-centric issues and implementation concern central topics arising from the literature review. The remaining four themes, focused on theoretical foundations, reflect upon the findings from the reviewed papers. Because the latest developments and future directions are emphasized, we focus on the top 20 marketing and information systems research (IS) journals, as they spearhead discussion in the field.

The paper next presents an overview of web personalization and its topical theoretical issues. Then, the methodology utilized in the review process is fully described. After this, results of the state-of-the-art review and the resulting ten major themes are presented and discussed. Theme-specific recommendations for future research are given. Then, conclusions are drawn from the results and the general future direction of the field is discussed. We also propose a conceptual division between extrapolated and interpolated web personalization. Finally, we consider the limitations of our approach. 


\section{Web personalization}

Personalization is a process whereby products and services are tailored to match individual preferences utilizing consumer data (Montgomery \& Smith 2009; Tuzhilin 2009). The process of personalization consists of learning customer preferences and synthesizing the gathered knowledge into offers, recommendations, and multiple versions of interaction touchpoints (Miceli, Ricotta \& Costabile 2007; Vesanen 2007). Consequently, the personalized outcome relies on estimates based on prior actions, ie., extrapolation. In essence, personalization enables one-to-one marketing (Peppers \& Rogers 1993), assuming that the creation of idiosyncratic value in the process forms a competitive advantage for the focal company.

Personalization is considered to be an umbrella term for preference matching (Miceli, Ricotta \& Costabile 2007; Sunikka \& Bragge 2008). Personalization is closely related to customization, which creates some inconsistencies around the use of the concepts (Arora et al. 2008; Fan \& Poole 2006; Sunikka \& Bragge 2012). There are clear overlaps within the terms, and they are sometimes used synonymously or nearly so (e.g., Miceli, Ricotta \& Costabile 2007; Parra \& Brusilovsky 2015; Singh et al. 2008; Zhang \& Wedel 2009). Most researchers distinguish personalization as a company-initiated, automatic process, whereas customization is user initiated (Fan \& Poole 2006; Ho \& Bodoff 2014; Montgomery \& Smith 2009; Sunikka \& Bragge 2012).

Web personalization is a sub-topic of personalization research (Tuzhilin 2009). The taxonomy between the concepts is not very clear, as personalization is commonly considered to be Internet related (Sunikka \& Bragge 2012), automated, and mostly concerning digital channels (e.g., Fan, Gordon \& Pathak 2006). Hence, personalization typically refers to web 
personalization, leading to the often interchangeable use of the terms. Traditionally, web personalization has been considered to be related to the personalization of websites (Eirinaki \& Vazirgiannis 2003) or e-commerce systems (Adolphs \& Winkelman 2010). While no clearcut definition exists, web personalization routinely covers personalization processes in the web environment, including the personalization of content, structure and other interaction touchpoints. Although Tuzhilin (2009) differentiates web personalization research from recommender systems research and user profiling, web personalization is considered to cover these streams (e.g., Brusilovsky, Kobsa \& Nejdl 2007; Chau et al. 2013; Johar, Mokherjee \& Sarkar 2014; Shinde \& Kulkarni 2012;). Thus, web personalization is the process of individualized matching to consumer preferences through automated processes in the web environment.

Web personalization is a focus area for multiple fields, especially for marketing and information systems (IS) research. Because web personalization addresses human-computer interaction, it is regularly examined in relation to technological applications. In fact, a majority of web personalization research has a technological focus, addressing topics such as recommender systems, data collection and processes, or user profiling (e.g., Adolphs \& Winkelman 2010; Sunikka \& Bragge 2012). While technological topics prevail, the multidisciplinarity of the field has resulted in versatile approaches, where technological approaches are supplemented with models from consumer research or psychology.

Only a few studies have considered the effect of the quality (Li \& Unger 2012) or usability (Murray \& Häubl 2009) of web personalization. Similarly, an on-going discussion revolves around whether web personalization has worthwhile effects for business. Ho and Bodoff (2014) find that web personalization is able to increase both advertising and sales revenues. 
Cao and Li (2007) propose that web personalization is the most effective tool in driving business success. Others (e.g., Thimuralai \& Sinha 2013), however, have found it difficult to prove that web personalization offers a boost to business performance. This may be because web personalization is appealing as a concept (Sunikka \& Bragge 2012) but is difficult to implement as a business tool. There is also a great deal of variety in what is synonymously considered web personalization. It is expected that 'personalization done' and ‘personalization done well’ produce different results (c.f. Fan \& Poole 2006). However, what constitutes 'personalization done well' keeps evolving, as both customer expectations and technological possibilities change.

Customer preferences are in the epicenter of web personalization. The success of web personalization relies on accurately detecting and then reacting to current preferences. However, preference finding is difficult (Chen et al. 2010). In the web personalization literature, preferences have often been viewed as static (Tuzhilin 2009), while in reality, contextual issues such as timing (Ho, Bodoff \& Tam 2011), location (Li et al. 2014), and phases in the buying process (Lambrecht \& Tucker 2013) keep preferences in a flux. The complexity of customer preferences and lack of knowledge of the contextual effects make it difficult to establish successful web personalization procedures.

\section{Methodology}

State-of-the-art reviews are necessary tools in furthering any academic study (Cooper 2010). The goal of state-of-the-art reviews is to provide a point of reflection on the present location and direction of the chosen field. Sunikka and Bragge (2012) also see review articles as gateways to solidifying research questions. There is a multitude of methods for conducting a 
state-of-the-art review, ranging from a free, iterative literature selection and description to a systematic review methodology. Both Cooper (2010) and Weed (2005) raise the issues that predetermination of theme selection and their descriptive nature are common flaws in literature reviews. These weaknesses can, at least to some extent, be overcome by a systematic review process, which has been considered to produce high reliability and quality when assessing large batches of literature (Denyer \& Tranfield 2006; Keränen, Piirainen \& Salminen 2012).

We have sought to combat the threat of focusing on predetermined themes by conducting as systematic a review as possible. However, four general themes were predetermined and we also use thematic analysis to build composites of our findings. While lessening the objectivity of a systematic approach, this allows us to form a clearer picture of the major developments in the field.

\section{The scope of the research}

This state-of-the-art review seeks to provide a comprehensive analysis of web personalization research, giving special attention to user-centric aspects, implementation and theoretical foundations. Due to the extensive literature available on the topic, the following filters have been administered to make a more in-depth analysis of the target articles possible. To begin, the period under review is restricted to the years 2005 - 2015 (May). This restriction allows us to chart the most recent developments in the field and focuses on a period beyond most prior literature reviews. Second, the focus is on business related issues, leaving other major topics such as learning and healthcare out of scope. Although personalization is a common theme in these research streams, the goals of these fields are qualitatively different from a business-centered view. Additionally, a decision to focus on the personalization of websites 
and web services means that mass customization and product customization have been omitted from the analysis. Finally, following Adolphs and Winkelman (2010), our analysis uses journal rankings to determine the quality of research. By focusing on the top 20 marketing and IS journals, the analysis includes research with the highest quality and impact. Our selection of journals comes from Academic Journal Guide (2015), published by the Chartered Association of Business Schools (ABS), and includes marketing and information systems journals.

\section{Search strategy}

We conducted a search within the target journals with the following search words: web personali*/customi*, website personali*/customi*, online personali*/customi*, e-commerce personali*/customi*, and electronic commerce personali*/customi*. Our search covered the abstract, title, and keywords. The stem of the terms personalization and customization were used in the search because our pre-analysis showed that both z- and s-forms of the terms are used in the literature. While this strategy produced a great increase in non-target articles, a higher inclusion rate of target-articles was possible. The search of target journals was conducted in May 2015.

With these criteria implemented, the search produced 504 (107 marketing, 397 IS) articles without duplicates. Our systematic review process followed Keränen, Salminen and Piirainen (2012) by forming a funneling process to segregate target articles from non-target articles, although our evaluation criteria differed. In the first phase, only articles published between 2005 and 2015 (May) were included. The second phase excluded articles that either did not mention personalization or customization in the article contents or in which these search items played minimal role. In addition, we examined whether articles were business related and 
excluded articles that dealt with areas such as gaming, education, and healthcare or particular function areas such as search. In the third and final phase of the segregation process, articles on mass customization, product customization and avatars were omitted from further analysis. This was due to the separation of these approaches from web personalization (see Sunikka \& Bragge 2012). We also omitted tourism-related articles but included news and advertising related articles. This selection was due to the latter being more business-related, offering contributions that were more generalizable. The articles were finally rechecked to ensure that they offered a significant contribution to the personalization discussion, which led to the exclusion of a few articles. The funneling process is summarized in Figure 1.

"Insert Figure 1 about here”

Ultimately, 91 articles (18 marketing and 73 IS) were identified for in-depth analysis. A listing of selected journal articles is provided in Appendix C.

\section{Theme formation and analysis}

We began by constructing composites for themes. This strategy proved its viability, as we first tried to implement Adolphs and Winkelman’s (2010) categorization structure for ecommerce personalization, which we found hard to apply to our dataset and our research goals. However, we follow Adolphs and Winkelman’s (2010) general structure that distinguishes (i) user-centric aspects, (ii) implementation issues, and (iii) theoretical foundations, as this division covers the over-arching themes in our dataset. User-centric aspects consider the interplay of human-computer interaction and the effects of web

personalization approaches on consumer behavior. Implementation covers issues in executing web personalization, such as findings on optimal interface designs or testing different types of 
recommender systems. Theoretical foundations address developing research models, study methods and general issues in web personalization.

\section{Results and discussion}

The topic of web personalization remained actively pursued throughout the analyzed period. The annual distribution of articles was relatively stable. The complete distribution of articles can be seen in Figure 2.

"Insert Figure 2 about here”

The findings suggest that web personalization continues to be an important topic in the top 20 marketing and IS journals. Given that the analysis only reached until May in 2015, a growing trend is possible.

There was significant variation in the distribution of selected articles in different journals, as marketing journals provided only a small portion of the selected articles, and many journals did not include any articles for further inspection. However, the discussion in the IS journals was active. Expert Systems with Applications accounted for one third of the entire dataset, with the top five contributing journals covering almost three quarters of the dataset. The top six contributing journals are listed in Table 1. A complete list of the article distribution among selected journals can be seen in Appendix A.

“Insert Table 1 about here” 
The results were somewhat expected, as web personalization plays varying roles in the top 20 marketing and IS journals. Additionally, prior research suggested that a focus on modeltesting research on recommender systems as well as data collection and processing would form a significant share of the dataset, thus explaining the centrality of Expert Systems with Applications in our dataset. However, the polarization between journals was higher than expected.

\section{User-centric aspects}

A total of 54 articles were categorized as having significant input in the category of usercentric aspects. This category is thus central to research efforts in web personalization during the analyzed period. Three main themes from the articles were identified: (a) privacy and trust, (b) satisfaction and loyalty, and (c) contextual issues. A detailed list of the selected usercentric aspects literature is shown in Table 2.

“Insert Table 2 about here”

\section{Theme \#1: Privacy and trust}

Privacy was the most discussed subclass for user specific aspects in our dataset. A clear consensus was formed in the dataset: breaches in privacy are maladaptive for a business. High personalization in online ads was found to increase feelings of intrusiveness and to harm business performance (van Doorn \& Hoekstra 2013). Awad and Krishnan (2006) expect consumers to be more willing to be profiled for websites than for online ads because the customer experiences greater potential benefit from profiling for websites. They suggest that companies only focus on customers who are willing to be profiled for personalization, as even 
additional privacy features were not effective in increasing participation of the unwilling group. However, the effects of privacy features may differ between use for commercial and social purposes (Chellapa \& Shivendu 2007; Lee, Ahn \& Bang 2011). Based on the findings (Awad \& Krishnan 2006; Li \& Unger 2012; Zhao, Lu \& Gupta 2012), there is a division between users who are willing and those who are unwilling to be profiled. However, studies have not reached consensus as to whether this division can be effectively mitigated by higher fit (van Doorn \& Hoekstra 2013), privacy controls or policies (Aguirre et al. 2015; Awad \& Krishnan 2006; Lee, Ahn \& Bang 2011; Tucker 2014; Zhao, Lu \& Gupta 2012) or incentives such as price reductions (Zhao, Lu \& Gupta 2012). Both Koch and Möslein (2005) and Lee, Ahn and Bang (2011) see user-led privacy controls as best practices.

Trust addresses how trustworthy users perceive either a web personalization technique (e.g., recommendations by a recommender system) or its provider to be. In web personalization, trust and privacy are often intertwined (e.g., Aguirre et al. 2015; Mukharjee \& Nath 2007). In our dataset, personalization was consistently positively related to trust (Komiak \& Benbasat 2006; Li \& Yeh 2010). Komiak and Benbasat (2006) see trust as being based on cognitive as well as emotional factors and report that perceived personalization significantly increases both, whereas Hong and Kim (2012) see trust as a means of segmentation for marketing personalization. Chau et al. (2013) studied distrust towards recommender systems and found that competence distrust has negative implications towards the use of recommender agents but integrity distrust based on biased product recommendation did not. Further, Martín-Vicente et al. (2012) discovered benefits from incorporating trust mechanisms in collaborative recommendations. 
Privacy and trust are closely knit concepts (Urban, Amyx, and Lorenzon (2009). However, they differ somewhat in their effects on overall personalization effectiveness and success. Privacy appears to be a hygiene factor in that increased security has a limited effect on boosting business performance, whereas breaches in security have a significant impact on business performance and trust. Privacy is also viewed as a precursor for trust and adoption willingness (Li \& Unger 2012). However, trust is considered to be both a precursor to successful personalization (e.g., Hong \& Kim 2012; Li, Wu \& Lai 2013) and an outcome of personalization (e.g., Komiak \& Benbasat 2006; Li \& Yeh 2010).

Privacy and trust suggest manifold interesting future research areas. To begin, it is important to gain further knowledge on the divergence between different customer groups in terms of their reactions toward privacy issues. Moreover, the effect of varying settings from commercial to social to foster trust is an interesting new direction for research. Second, the role of the user in the privacy discussion could be deepened by studying whether users would perceive security breaches differently if they personally contributed to the incident and whether communicating the role of the user in detected security breaches would mitigate the negative impact. Finally, longitudinal studies might reveal important aspects of how the negative/positive impact of created/lost trust and privacy effects may wear off.

Theme \#2: Satisfaction and loyalty

Customer satisfaction was an actively studied concept in our dataset. Some contradicting evidence was found regarding the link between personalization and satisfaction. In most studies, personalization was found to have a strong positive impact on satisfaction by some 
(Devaraj, Fan \& Kohli 2006; Ha, Muthaly \& Akamavi 2010; Herrington \& Weaven 2009), whereas not significant effects were also reported (Kim, Kim \& Kandampully 2009). Liang, Lai and $\mathrm{Ku}$ (2006) suggest that the effect of personalization on satisfaction could also be indirect and moderated by the motivation of the user. Customer satisfaction also played a role in many other articles, although they were not classified in this section. Moreover, customer satisfaction was found to be intertwined with consumer loyalty.

The consumer/customer loyalty subclass was built to integrate the commitment, revisit intention and repurchase intention literature under consumer loyalty. Similarly to customer satisfaction, our dataset proposes contradictory findings on whether personalization generates consumer loyalty. Some find support for the claim that web personalization, at least indirectly, positively influences the formation of consumer loyalty (Chang \& Chen 2008; Ha, Muthaly \& Akavami 2010; Mukherjee \& Nath 2007; Zhang, Agarwal \& Lucas 2011). Tsai and Huang (2007) go as far as to suggest that personalization is a necessary condition of maintaining loyalty but not sufficient in itself. However, other recent articles did not report a positive relationship between the two (Che et al. 2015; Thirumalai \& Sinha 2013). Che et al. (2015) noted the possible moderating effect of the type of consumers based on whether they come from either direct or affiliate visiting channels.

Satisfaction and loyalty are key concepts in web personalization because they are considered essential drivers of business performance. It is difficult to conceptualize successful web personalization if it does not have a positive effect on satisfaction and loyalty. However, the results do not unquestionably confirm this in our dataset. The issue also relates to the more general question of whether web personalization is effective and worthwhile, which will be discussed in more detail in Theme \#10. 
The results further indicate that a more general and more detailed approach to measuring the direct and indirect effects of web personalization on satisfaction and loyalty is needed. A meta-study might reveal these specific effects and further confirm the expected positive relationships between the concepts. However, while some variation in these results is expected, the variation in our dataset appears to be quite high and calls for further inspection. A more detailed approach in studying (a) what type of web personalization was used, (b) in what setting and on which type of users, and (c) the interplay in the effect on satisfaction, loyalty and its sub-dimensions such as attitudinal and behavioral loyalty and web personalization might bring out new insights or at least help to understand the current variation in results. The inclusion of contextual factors in these analyses is suggested.

\section{Theme \#3: Contextual factors}

The inclusion of contextual factors is a relatively new trend in web personalization (Sunikka \& Bragge 2012). Contextual factors contribute both new areas to personalize as well as a new dimension for assessing the effects of web personalization. In our dataset, three major subclasses were identified: (i) cultural effects, (ii) timing, and (iii) personal disposition.

Cultural effects on consumer behavior recognize the power of culture as a context for interaction in changing the way consumers react to web personalization. The results from the dataset appear to disagree substantially. A study on young Korean and UK customers’ purchasing attitudes found no significant cultural effect (Ha, Muthaly \& Akamavi 2010), whereas Hispanic communities in the US tested for moderate preference for culturally 
customized web content (Singh et al. 2008). However, both Reinecke and Bernstein (2013) and Gevorgyan and Manucharova (2009), investigating differences between US and Chinese users, underline the importance of cultural effects in web design. Further, Steenkamp and Geyskens (2006) found the effect of customization on the perceived value of websites to be higher in countries where national-cultural individualism is higher.

Timing refers to the contextual effect of either clock time or situational time in the personalization process and its effect on consumer behavior. One central theme in the reviewed literature was the effects of lifecycle in personalization and recommendation accuracy (Blanco-Fernández et al. 2010; Hong, Li \& Li 2012; Li et al. 2014). Another theme was when to show personalized content to consumers and what type to show (Ho, Bodoff \& Tam 2011; Li et al. 2014). Moreover, Lee, Park, and Park (2009; 2008) found that recommendation approaches fueled by temporal dynamics provide better results.

Personal disposition is a composite subclass of our dataset, including topics such as personality, attitudes, and motivation. Tam and Ho’s (2005) findings suggest that users with low motivational levels for cognitive effort are more likely to comply with suggestions from recommender agents. Ho and Bodoff (2014) created a model on how attitude influences both item sampling and selection processes. Martin, Sherrard and Wentzel (2005) found that sensation-seekers prefer more complex visual designs than users with low sensation-seeking levels. Capuano et al. (2015) systematized a process for extracting customer personality measurements through social activity.

While there is significant variation in the results for different specific contextual factors, the general view supports the notion that the user's context is an important driver in determining 
web personalization success. Our dataset shows that timing or temporal dynamics are of key importance. However, the effects of context should be considered as a matrix: some contextual factors support and some hamper successful web personalization in a given sample. For example, successful timing could be determined by a fit with a current motivational state that is in part activated by cultural and environmental cues (e.g., Griskevicius \& Kenrick 2013). Unfortunately, a coherent framework that would consider contextual effects on web personalization is currently lacking.

Direction for future research in the contextual factors of web personalization could include (i) reviewing current studies on the effect sizes of different contextual factors on web personalization to estimate the overall effect, (ii) finding relationships between different contextual factors to build more advanced models, and (iii) turning the tables—studying not just what effects a given contextual factor has on web personalization but how a certain personalization procedure influences the role of contextual factors.

We find advanced contextual factors as the primary direction for future research as it complements many of the main sub-topics such as recommender systems, data collection and processing, and user-specific aspects overall. Further, we find that applications of web personalization should consider not only such basic contextual factors as time of day or distance to a physical location but advance to include more psychologically complex issues such as motivation and emotions. This kind of advanced contextualization is undoubtedly difficult to achieve but it could be a key driver in making web personalization more worthwhile for the user. 


\section{Implementation}

A total of 47 articles focused on various aspects of implementing web personalization. The three major subclasses were design/interface, recommender systems and data processing. Of these three, recommender systems (17 articles) and data processing (15 articles) were the most active subclasses in our dataset. A detailed list of the selected implementation literature is shown in Table 3.

“Insert Table 3 about here”

Theme \#4: Design factors

Design/interface covers the means and effects of personalization in web design. Our dataset did not produce any coherent clusters of research but rather highlighted the variety in this subclass. Both Reinecke and Bernstein (2013) and Gevorgyan and Manucharova (2009) discussed the cultural dimension of design. Others focused on the effects of personalization or customization, arguing that design can increase trust (Li \& Yeh 2010) and loyalty (Chang \& Chen 2008) as well as shape preferences (Seneler, Basoglu \& Daim 2009). Users prefer medium complexity in web design elements on average, but user groups differ in this regard (Martin, Sherrard \& Wentzel 2005). Similarly, Wang, Minor and Wei (2011) recommend integrating different aesthetic dimensions into web personalization based on different motivational states of the user. Finally, Parra and Brusilovsky (2015) tested user controllability in a recommender system interface for increasing engagement. 
The results suggest two things. First, an understanding of design factors is essential in successful web personalization. Second, while limited in scope, design personalization appears to be beneficial regardless of whether it is user controlled or automatic. This also pinpoints interesting future research avenues. A comparative study on user controlled versus automatic personalization in different web channels could reveal interesting insights into what makes design personalization effective. Moreover, the broadness of design factors calls for a review article specialized on the design factors in web personalization.

Theme \#5: Recommender system implementation

Recommender systems or recommender agents refer to the automatized recommendation of products, services and content to users. Our dataset consisted of all three popular approaches to recommender systems (Jiang, Shang \& Liu 2010), including collaborative filtering (e.g., Lee, Park \& Park 2008), content-based (e.g., Li et al. 2014), and particularly different types of hybrid (e.g., Albadvi \& Shahbazi 2009; Hung 2005; Li, Lu \& Xuefeng 2005; Shinde \& Kulkarni 2012) approaches. Discussion in this subclass has been active and varied. The methods of acquiring recommendation accuracy and focus in development vary greatly. Many approaches with different focus areas exist, such as maximizing customer's after-use gratification (Jiang, Shang \& Liu 2010), using social relations (Li, Wu \& Lai 2013), temporal interest (Li et al. 2014), clustering (Shinde \& Kulkarni 2012; Zheng et al. 2013), causal maps (Lee \& Kwon 2008), product taxonomy (Hung 2005), graph partitioning (Jalali et al. 2010), and analytic hierarchy processing (Chen et al. 2010) as well as associative- (Zhang \& Jiao 2007) and fuzzy-based examination (Cao \& Li 2007) as a basis for recommendations. Lee and Huang (2011) applied recommender systems to green shopping; Lin et al. (2010) constructed 
a salesman-like solution, and Lee, Choi and Suh (2013) used their recommender system to recommend sellers instead of products.

A clear trend of rising complexity in approaches can be established between the earlier (e.g., Hung 2005) and more recent articles (Li et al. 2014; Li, Wu \& Lai 2013). This finding is in line with the suggestions of a literature review by Gao, Li and Wu (2010) to extend recommender systems research. Another finding is that contextual factors are still an underresearched topic, but temporal effects in particular have received growing interest. There has already been some research to basic temporal dynamics, which is encouraged to continue. However, as mentioned above, advanced contextualization should take into account more complex factors such as motivation and emotions. We see that all three popular categories of approaches (collaborative, content-based, and hybrid) continue to be fertile ground for new research if coupled with more advanced techniques in user profiling with contextual data.

Theme \#6: Data collection and processing

Data collection and processing involves methods of acquiring data for customer profiling and processing it for use in web personalization either through or for recommender systems or other applications. This subclass primarily considered three types of approaches. First, some articles focused on the user, trying to extract and process data on personality (Capuano et al. 2015), product-specific knowledge and interior desire (Chou et al. 2010), reputation and expertise (Martín-Vicente et al. 2012), or implicit needs (Chang et al. 2009). Second, information on product views and clickstream behavior was applied for user identification 
(Yang 2010), psychographic segmentation (Hong \& Kim 2012), customer life-cycle stage assessment, and the enhancement of collaborative filtering (Ahn, Kang \& Lee 2010). Finally, several techniques were suggested, such as two-stage models for information routing (Fan, Gordon \& Pathak 2006), back-propagation for association rules (Huang et al. 2008), metadata and semantic reasoning (Blanco-Fernández et al. 2010), and a two-step Apriori Algorithm for assessing the type of behavior. In particular, the recent literature (e.g., Colace et al. 2015) suggests combining several inputs in data collection and processing.

Data collection and processing is advanced and continues to produce meaningful insights. Our dataset suggests that similar to recommender systems, the needed expansion should address the psychological features of users and a better understanding of the layers of context in question. Future research directions should converge with the latest advances in psychology to find new material for processing. These might include approaches such as regulatory focus (Higgins 1997) and regulatory fit (Higgins 2000), as well as Fundamental Motives Framework (Griskevicius \& Kenrick 2013; Kenrick et al. 2010a; Kenrick et al. 2010b), as these theories suggest predictable changes in behavior, which may enable computational modeling.

\section{Theoretical foundations}

Within the theoretical foundations, we focus on the following general themes: (a) the research methodology used, (b) the roles of the fields of marketing and information systems in the web personalization literature, (c) the conceptualization of web personalization versus that of web customization, and (d) whether personalization provides value. We identified 18 articles in our categorization that focused on a broad variety of theoretical foundations but because 
many other articles had insights to contribute to the literature, our analysis here concerns the overall dataset.

Theme \#7: Research methodology

A variety of research methodologies were applied in the reviewed studies. Experiments were the prevailing method, with 55 of 91 articles applying some form of experiment and seven articles making use of one or multiple field experiments. The experiments, however, relied heavily on model testing, as approximately one third (29 articles) are classified in this category. These, for the most part, dealt with testing the recommendation accuracy of recommender systems. This was an expected result, as Sunikka and Bragge (2008) reported similar results. In addition, surveys and questionnaires were the second largest method group (21 articles), followed by conceptual studies (9 articles). Qualitative methods such as interviewing and focus groups were only found in two articles (Matchwick, Wagner \& Unni 2010; Singh et al. 2008).

We support the reliance on experiments. Web personalization often addresses issues that require quantitative verification or refers to changes that influence users subconsciously. Much of the work concerns recommendation accuracy, which is difficult to study without experimenting. However, we propose two amendments. First, although field experiments are present, increasing their number would help to cement the applicability of a given research finding to practice. Laboratory experiments are good in that they are very precise. Users, however, encounter web personalization practices in conjunction with other stimuli that affect their overall experience. Second, the inclusion of qualitative methods could enrich and 
broaden the data, especially that on on user-centric aspects. While behavioral or attitudinal research might tell us about the overall effect of web personalization practice, inspecting it through a qualitative lens could reveal aspects of user experience. Interviews and ethnographic methods are already widely used in other fields of user testing, and they are sometimes used in pre-testing in web personalization. Best practices from user testing should be applicable to web personalization also.

All of the research in our dataset focused on the immediate impacts on web personalization. A longitudinal approach was absent. This is partly understandable, as the field is evolving rapidly. However, even a time span of one or two years could shed light on the effects of web personalization in the long-term—something that the field is currently lacking.

Theme \#8: The roles of the marketing and IS literature in web personalization

Web personalization is a multi-faceted field on which many other fields converge. The fields of information systems and marketing are both central to the overall discussion. However, as evident in our dataset of 73 IS articles and 18 marketing articles, web personalization is much more prominent in IS studies than in marketing. This becomes even more highlighted when considering that although central enough to be included in our analysis, some marketing articles were not solely focused on web personalization issues. This raises questions of whether marketing scholars feel that they have little to say regarding web personalization or if web personalization is simply sidelined from other focus areas. The latter suggestion appears to be unfounded, as the importance of digital channels and impact of quality service via 
digital channels continues to grow, and personalization is an important topic in marketing (Goldsmith \& Freiden 2004; Kalaignaman, Kushwaha \& Veradarajan 2008).

The IS literature is very focused on recommender systems and data processing. This area is actively studied, and the sub-field has advanced during the analyzed period. The ability to find better algorithms and data mining methods has continued to improve rapidly, yet the area has become more complex. We suggest that constructing more complex algorithms could benefit from the input of marketing studies, especially consumer behavior and consumer psychology. This is to say that the technological advances of IS scholars are the motor of advancing web personalization, but the motor must run on a deeper understanding of consumer psychology. A meaningful division of effort between the fields might be that marketing scholars produce actionable models on consumer behavior on which IS scholars advance their algorithms.

Theme \#9: Web personalization vs. web customization

As stated, the concepts of personalization and customization have been confused in the past (Arora et al. 2008). In their review, Sunikka and Bragge (2012) found support for consensus, defining personalization as a company-driven process in the web environment.

Customization, meanwhile, is a user-initiated process that matches needs with offerings. Our review supports this definition, as the articles in our dataset followed this division with few exceptions (e.g., Miceli, Ricotta \& Constable 2007; Singh et al. 2008). While web personalization and web customization continue to be two sides of the same coin, thus providing synergies by including both approaches, this evolution toward distinction between the terms is welcomed because it will help clarify the field. 
Also, the terms “personalization” and "web personalization” appear to be used interchangeably. There are benefits in not differentiating the terms; personalization is internetrelated (Sunikka \& Bragge 2012), making it difficult to draw a line between the terms. However, there are also differences, as web personalization focuses on the web environment, which has a somewhat idiosyncratic nature. The confusion between the terms resulted in difficulty searching for and outlining research on web personalization. Hence, it is suggested that researchers ought to discuss this division to clarify their approach.

Theme \#10: Web personalization effectiveness for business results

The variety of approaches in the dataset makes it difficult to examine the effects of web personalization on business results. Further, according to the dataset, although business results appear to be discussed, they are often not the focal topic. There is some general support for the positive business effects of web personalization in the dataset. Ho and Bodoff (2014) claim that web personalization is able to increase both advertising and sales revenues, whereas Cao and Li (2007) note the general assumption that personalization is the most effective tool for driving business success. However, Thimuralai and Sinha (2013), in terms of customer loyalty through personalization, and Tsai and Huang (2007), for purchase intention through customization, did not find support for a boost in business performance. Cultural effects work as a prime example of this variation: Singh et al. (2008) and Gevorgyan and Manucharova (2009) found cultural effects important for business-related goals supported by Steenkamp and Geyskens (2006), whose study partially supported this finding. However, Ha, Muthaly and Akamavi (2010) report not-significant effects. Moreover, the results appear 
to vary greatly depending on many contextual factors such as the type of customers (Che et al. 2015), buying process phase (Lambrecht \& Tucker 2013), and timing (Ho \& Bodoff 2014; Hong, Li \& Li 2012). Given the fluctuating nature of customer preferences, the effect of a single web personalization procedure is likely to change over time as customer expectations and habits change.

We suggest that researchers place greater emphasis on uncovering the relationship between web personalization and business outcomes. A meta-study could reveal important aspects of the overall effects of web personalization for businesses. Further, current studies often focus on "soft” business goals such as customer satisfaction, customer loyalty (especially cognitive, attitudinal and conative aspects) or trust rather than "hard” primary business goals such as increased sales, customer lifetime value (CLV) or lower marketing costs. Knowledge on direct business goals would clarify the role and importance of web personalization in driving business success. We consider field experiments important in gathering this knowledge. Overall, this development would also facilitate the application of web personalization research results to practice.

A complete list of the selected literature with the significant sub-categories identified is listed in Appendix B.

\section{Conclusion}

This research contributes to the web personalization literature by giving an over-arching view of issues in web personalization found in published articles from the top 20 marketing and IS journals. A focus on top ranked journals was chosen, as these outlets should spearhead the discussion of web personalization. Our focus areas were plentiful, including most discussed 
themes, general theoretical issues such as terminology, the division of interest between different academic fields, methodologies applied, and especially research gaps and future trends.

Web personalization is relatively actively discussed in the top 20 marketing and IS journals. The discussion, however, is polarized in two manners. Firstly, IS journals dominate the discussion, with marketing journals having less impact. The focus appears to be on technological applications, even when discussing user-centric issues. This calls for a more active dialogue from marketing scholars, who could share insights from the consumer psychology and consumer behavior literature to apply to the technological applications being developed. Secondly, a few of the forty journals dominated in terms of output numbers. As web personalization research appears to evolve around technological advances, journals such as Expert Systems with Applications expectedly take the leading role in the overall discussion.

We identified ten themes, which we categorized into three groups: user-centric issues, implementation and theoretical foundations. The top themes in user-centric issues were (i) privacy and trust, (ii) satisfaction and loyalty, and (iii) contextual issues. Privacy issues continue to be central but appear to be a hygiene factor, whereas trust works as glue on many dimensions in web personalization. The role of satisfaction and loyalty as predictors of web personalization success is debatable. A metastudy could provide more detailed insights into the overall effects of web personalization on satisfaction and loyalty. Contextual issues dealing with web personalization continue to be identified and the trend has room to grow. Issues such as timing, motivational state, and cultural effects are fertile ground for scholars to build upon. We see contextual issues as the dominant stream for future research, as their complexity unveils an abundance of different possible effects to be researched. 
Issues in implementation primarily addressed three themes: (i) design/interface, (ii) recommender systems, and (iii) data collection and processing. Design and interface issues covered the role of the user as an initiator of design changes and the role of design in web personalization success. Recommender systems and data collection and processing methods are receiving the most interest from researchers and are advancing rapidly. There are two trends here. One trend shows an increase in integration between different recommender and data collection methods, where the array of methods continue to contribute both individually and together in hybrid forms. The other trend focuses on enhancing recommendations with broader and deeper contextual data.

The established themes covered in the theoretical foundations included (i) research methods, (ii) the division of labor between the fields of marketing and IS, (iii) terminological issues between web personalization and web customization, and (iv) the effectiveness of web personalization in driving business results. The most commonly used method was experiments, especially model testing. The lack of qualitative methods and longitudinal study designs was striking. The field of information systems is actively producing advances for many different avenues. Marketing insights, however, would be welcome in enriching these developments, but this area currently lacks momentum.

Our study also confirms the terminology division between web personalization and web customization (Sunikka \& Bragge 2012). Web personalization is a firm-controlled activity that matches current user-specific needs with appropriate content, design and functionality. Web customization, however, addresses similar issues but is user-controlled. There is considerable variance in results concerning the effectiveness of web personalization in driving 
business success. This topic calls for special examination and more research specifically considering the primary business goals of increasing sales and lowering marketing cost. This conclusion is also our secondary general suggestion for future research.

The field of web personalization continues to expand and advance rapidly. There has been a clear shift from the old days, when the key question was how to do it, to more a sophisticated discussion on how to do it well (c.f. Fan \& Poole 2006). However, the question of whether web personalization is effective for business appears to be an inquiry into how and where web personalization is implemented. This is an important development for both theory and practice. While the effectiveness of web personalization remains somewhat debatable, the methods for acquiring business results developed convincingly during the analyzed timeframe. There is a minor difficulty with fragmentation in the field, as novel possibilities appear mostly due to technological advances. In addition, markers of unification exist, as the terminology around web personalization is more or less cemented.

\section{Recommendations for future research}

This literature review offers fertile avenues for further research in this domain. As discussed earlier in this article, web personalization will evolve around the increasing complexity of calculable elements such as contextual factors. There are still new opportunities from converging different recommendation techniques with new contextual elements. One future direction is likely to be the integration of these various approaches. Moreover, the issue of timing is still underresearched. With the temporal aspect of web personalization, the procedures can only produce suggestions for what the user usually wants and not what is wanted right now. The study of timing coupled with different psychological models (e.g., regulatory fit or fundamental motives framework) should be fruitful, especially if methods for 
more immediate web personalization are developed. Such possibilities are not farfetched, as the facial recognition of moods, for example, is rapidly evolving (Zhang, Zhang \& Hossain 2015). This development further directs focus toward advancing and integrating psychological elements into web personalization approaches. Advanced contextualization that takes the emotions and currently active motives of users into account should be the primary focus of future research. Still, the effects of ever more complex approaches should be measurable using direct business results to both verify end goal effectiveness and clarify the field for practice. Thus, we suggest this line of research as the secondary future research direction.

In another direction, we see potential avenues for research in further expanding the classification of web personalization. We suggest defining two forms of web personalization: extrapolated and interpolated. The basic idea of web personalization revolves around estimating the desired personalized outcome version for the focal user based on previous usage patterns. Thus, the personalized outcome version is based on extrapolation. A great majority of, if not all, articles in our dataset relied on extrapolating personalization. We see the possibility for complementing this main form of web personalization with interpolated web personalization. By interpolated web personalization, we mean that a chosen element is intersected with the web environment to prime a chosen motive that guides user behavior in a predictable way. For instance, product choice can be affected through the different website backgrounds and pictures utilized (Mandel \& Johnson 2002). In extrapolated web personalization, it is difficult to estimate immediate preferences. Consequently, the value of the interpolated approach could be that primes act as beacons to guide personalization processes and facilitate finding a point of reference. 
The interpolated approach should be viewed as a complementary tool to extrapolated approaches. Moreover, the interpolated approach requires testing and calls for a better understanding of motives in digital channels.

\section{Limitations}

Our results must be evaluated in the light of certain key limitations. First, while offering clear benefits, our dataset only covers the top 20 marketing and IS journals. This leaves a plethora of other high quality outlets, such as other journals, books, and conference papers, out of our analysis. The excluded set of articles provides room for a more general review in the future. Moreover, we utilized only web databases in our search, potentially excluding relevant articles due to limitations of the database search tools and keyword selection. Second, our focus on business-related studies potentially discarded relevant findings made in other contributing areas of web personalization such as education, gaming, tourism, healthcare or mass customization. Inspection of these neighboring areas might reveal insights that are shared between them and an understanding of what is unique to each. Third, the chosen time span of 2005 to 2015 (May) is a compromise between scope and timeliness. Major insights that still influence web personalization today have been made prior to our chosen time span. However, it is possible that due to the rapid evolution of web personalization, just five years erodes the currency of earlier findings, especially in the case of web personalization technologies. Thus, it is possible that the most recent findings are somewhat diluted by the inclusion of older entries. However, we believe that we found a good balance of scope and immediacy in light of our research questions. Finally, we chose to identify ten themes out of our dataset, leaving some minor themes in the periphery. We felt that this was appropriate for clarity and because of the impact we see for the chosen themes. However, many interesting 
developments are being made outside of these themes. Server capacity in the case of implementation and perceived interactivity in the case of user specific aspects serve as examples of relevant but not major themes in our dataset. Future reviews can work as points of reflection on the evolution of these underlying themes. 


\section{References}

Adolphs, C., \& Winkelmann, A. (2010). Personalization Research in E-Commerce-A State of the Art Review (2000-2008). Journal of Electronic Commerce Research, 11(4), 326-341.

Aguirre, E., Mahr, D., Grewal, D., de Ruyter, K., \& Wetzels, M. (2015). Unraveling the Personalization Paradox: The Effect of Information Collection and Trust-Building Strategies on Online Advertisement Effectiveness. Journal of Retailing, 91(1), 34-49.

Ahn, H. J., Kang, H., \& Lee, J. (2010). Selecting a small number of products for effective user profiling in collaborative filtering. Expert Systems with Applications, 37(4), 3055-3062.

Albadvi, A., \& Shahbazi, M. (2009). A hybrid recommendation technique based on product category attributes. Expert Systems with Applications, 36(9), 11480-11488.

Al-Shamri, M. Y. H. (2014). Power coefficient as a similarity measure for memory-based collaborative recommender systems. Expert Systems with Applications, 41(13), 5680-5688.

Arora, N., Dreze, X., Ghose, A., Hess, J. D., Iyengar, R., Jing, B., ... \& Zhang, Z. J. (2008). Putting one-to-one marketing to work: Personalization, customization, and choice. Marketing Letters, 19(3-4), 305-321.

Awad, N. F., \& Krishnan, M. S. (2006). The personalization privacy paradox: an empirical evaluation of information transparency and the willingness to be profiled online for personalization. MIS quarterly, 13-28. 
Blanco-Fernández, Y., Pazos-Arias, J. J., López-Nores, M., Gil-Solla, A., Ramos-Cabrer, M., García-Duque, J., ... \& Díaz-Redondo, R. P. (2010). Incentivized provision of metadata, semantic reasoning and time-driven filtering: Making a puzzle of personalized e-commerce. Expert Systems with Applications, 37(1), 61-69.

Brusilovsky, P., Kobsa, A., \& Nejdl, W. (eds.) (2007). The Adaptive Web: Methods and Strategies of Web Personalization, Lecture Notes in Computer Science (Vol. 4321). Berlin: Springer Science \& Business Media.

Cao, Y., \& Li, Y. (2007). An intelligent fuzzy-based recommendation system for consumer electronic products. Expert Systems with Applications, 33(1), 230-240.

Capuano, N., D’Aniello, G., Gaeta, A., \& Miranda, S. (2015). A personality based adaptive approach for information systems. Computers in Human Behavior, 44, 156-165.

Chang, S. E., Changchien, S. W., \& Huang, R. H. (2006). Assessing users' product-specific knowledge for personalization in electronic commerce. Expert Systems with Applications, 30(4), 682-693.

Chang, H. H., \& Chen, S. W. (2008). The impact of customer interface quality, satisfaction and switching costs on e-loyalty: Internet experience as a moderator. Computers in Human Behavior, 24(6), 2927-2944. 
Chang, C. C., Chen, P. L., Chiu, F. R., \& Chen, Y. K. (2009). Application of neural networks and Kano’s method to content recommendation in web personalization. Expert Systems with Applications, 36(3), 5310-5316.

Chau, P. Y., Ho, S. Y., Ho, K. K., \& Yao, Y. (2013). Examining the effects of malfunctioning personalized services on online users' distrust and behaviors. Decision Support Systems, 56, 180-191.

Che, T., Peng, Z., Lim, K. H., \& Hua, Z. (2015). Antecedents for consumers’ intention to revisit an online group-buying website: a transaction cost perspective. Information \& Management.

Chellappa, R. K., \& Shivendu, S. (2007). An economic model of privacy: A property rights approach to regulatory choices for online personalization. Journal of Management Information Systems, 24(3), 193-225.

Chen, D. N., Hu, P. J. H., Kuo, Y. R., \& Liang, T. P. (2010). A Web-based personalized recommendation system for mobile phone selection: Design, implementation, and evaluation. Expert systems with Applications, 37(12), 8201-8210.

Choi, J., Lee, H. J., \& Kim, Y. C. (2011). The influence of social presence on customer intention to reuse online recommender systems: the roles of personalization and product type. International Journal of Electronic Commerce, 16(1), 129-154. 
Chou, P. H., Li, P. H., Chen, K. K., \& Wu, M. J. (2010). Integrating web mining and neural network for personalized e-commerce automatic service. Expert Systems with Applications, 37(4), 2898-2910.

Colace, F., De Santo, M., Greco, L., Moscato, V., \& Picariello, A. (2015). A collaborative user-centered framework for recommending items in Online Social Networks. Computers in Human Behavior.

Cooper, H. (2010). Research synthesis and meta-analysis: A step-by-step approach (4 ${ }^{\text {th }}$ edition). Thousand Oaks: Sage Publications.

Da Silva, V. R., \& Alwi, F. S. S. (2008). Online brand attributes and online corporate brand images. European Journal of Marketing, 42(9/10), 1039-1058.

Denyer, D., \& Tranfield, D. (2006). Using qualitative research synthesis to build an actionable knowledge base. Management Decision, 44(2), 213-227.

Devaraj, S., Fan, M., \& Kohli, R. (2006). Examination of online channel preference: using the structure-conduct-outcome framework. Decision Support Systems, 42(2), 1089-1103.

Eirinaki, M., \& Vazirgiannis, M. (2003). Web mining for web personalization. ACM Transactions on Internet Technology (TOIT), 3(1), 1-27.

Fan, W., Gordon, M. D., \& Pathak, P. (2006). An integrated two-stage model for intelligent information routing. Decision Support Systems, 42(1), 362-374. 
Fan, H., \& Poole, M. S. (2006). What is personalization? Perspectives on the design and implementation of personalization in information systems. Journal of Organizational Computing and Electronic Commerce, 16(3-4), 179-202.

Gao, M., Liu, K., \& Wu, Z. (2010). Personalisation in web computing and informatics: Theories, techniques, applications, and future research. Information Systems Frontiers, 12(5), 607-629.

Gedikli, F., Jannach, D., \& Ge, M. (2014). How should I explain? A comparison of different explanation types for recommender systems. International Journal of Human-Computer Studies, 72(4), 367-382.

Gevorgyan, G., \& Manucharova, N. (2009). Does culturally adapted online communication work? A study of American and Chinese Internet users' attitudes and preferences toward culturally customized Web design elements. Journal of Computer-Mediated Communication, 14(2), 393-413.

Goldsmith, R. E., \& Freiden, J. B. (2004). Have it your way: consumer attitudes toward personalized marketing. Marketing Intelligence \& Planning, 22(2), 228-239.

Griskevicius, V., \& Kenrick, D. T. (2013). Fundamental motives: How evolutionary needs influence consumer behavior. Journal of Consumer Psychology, 23(3), 372-386. 
Ha, H. Y., Muthaly, S. K., \& Akamavi, R. K. (2010). Alternative explanations of online repurchasing behavioral intentions: A comparison study of Korean and UK young customers. European Journal of Marketing, 44(6), 874-904.

Herington, C., \& Weaven, S. (2009). E-retailing by banks: e-service quality and its importance to customer satisfaction. European Journal of Marketing, 43(9/10), 1220-1231.

Higgins, E. T. (2000). Making a good decision: value from fit. American psychologist, 55(11), 1217.

Higgins, E. T. (1997). Beyond pleasure and pain. American psychologist, 52(12), 1280.

Ho, S. Y., \& Bodoff, D. (2014). The effects of Web personalization on user attitude and behavior: An integration of the elaboration likelihood model and consumer search theory. MIS Quarterly, 38(2), 497-520.

Ho, S. Y., Bodoff, D., \& Tam, K. Y. (2011). Timing of adaptive web personalization and its effects on online consumer behavior. Information Systems Research, 22(3), 660-679.

Hong, T., \& Kim, E. (2012). Segmenting customers in online stores based on factors that affect the customer's intention to purchase. Expert Systems with Applications, 39(2), 21272131.

Hong, W., Li, L., \& Li, T. (2012). Product recommendation with temporal dynamics. Expert Systems with Applications, 39(16), 12398-12406. 
Huang, Y. P., Chuang, W. P., Ke, Y. H., \& Sandnes, F. E. (2008). Using back-propagation to learn association rules for service personalization. Expert Systems with Applications, 35(1), 245-253.

Hung, L. P. (2005). A personalized recommendation system based on product taxonomy for one-to-one marketing online. Expert systems with applications, 29(2), 383-392.

Jalali, M., Mustapha, N., Sulaiman, M. N., \& Mamat, A. (2010). WebPUM: A Web-based recommendation system to predict user future movements. Expert Systems with Applications, 37(9), 6201-6212.

Jiang, Y., Shang, J., \& Liu, Y. (2010). Maximizing customer satisfaction through an online recommendation system: A novel associative classification model. Decision Support Systems, 48(3), 470-479.

Johar, M., Mookerjee, V., \& Sarkar, S. (2014). Selling vs. Profiling: Optimizing the Offer Set in Web-Based Personalization. Information Systems Research, 25(2), 285-306.

Kabassi, K. (2010). Personalizing recommendations for tourists. Telematics and Informatics, 27(1), 51-66.

Kalaignanam, K., Kushwaha, T., \& Varadarajan, P. (2008). Marketing operations efficiency and the Internet: An organizing framework. Journal of Business Research, 61(4), 300-308. 
Kang, H., \& Sundar, S. S. (2013). Depleted egos and affirmed selves: The two faces of customization. Computers in Human Behavior, 29(6), 2273-2280.

Kenrick, D. T., Griskevicius, V., Neuberg, S. L., \& Schaller, M. (2010). Renovating the pyramid of needs contemporary extensions built upon ancient foundations. Perspectives on psychological science, 5(3), 292-314.

Kenrick, D. T., Neuberg, S. L., Griskevicius, V., Becker, D. V., \& Schaller, M. (2010). GoalDriven Cognition and Functional Behavior The Fundamental-Motives Framework. Current Directions in Psychological Science, 19(1), 63-67.

Keränen, J., Piirainen, K. A., \& Salminen, R. T. (2012). Systematic review on B2B branding: research issues and avenues for future research. Journal of Product \& Brand Management, 21(6), 404-417.

Kim, J. H., Kim, M., \& Kandampully, J. (2009). Buying environment characteristics in the context of e-service. European Journal of Marketing, 43(9/10), 1188-1204.

Koch, M., \& Möslein, K. M. (2005). Identities management for e-commerce and collaboration applications. International Journal of Electronic Commerce, 9(3), 11-29.

Komiak, S. Y., \& Benbasat, I. (2006). The effects of personalization and familiarity on trust and adoption of recommendation agents. Mis Quarterly, 941-960. 
Lambrecht, A., \& Tucker, C. (2013). When does retargeting work? Information specificity in online advertising. Journal of Marketing Research, 50(5), 561-576.

Lazcorreta, E., Botella, F., \& Fernández-Caballero, A. (2008). Towards personalized recommendation by two-step modified Apriori data mining algorithm. Expert Systems with Applications, 35(3), 1422-1429.

Lee, D. J., Ahn, J. H., \& Bang, Y. (2011). Managing consumer privacy concerns in personalization: a strategic analysis of privacy protection. MIS Quarterly, 35(2), 423-444.

Lee, S., Choi, K., \& Suh, Y. (2013). A personalized trustworthy seller recommendation in an open market. Expert Systems with Applications, 40(4), 1352-1357.

Lee, Y. L., \& Huang, F. H. (2011). Recommender system architecture for adaptive green marketing. Expert Systems with Applications, 38(8), 9696-9703.

Lee, K. C., \& Kwon, S. (2008). Online shopping recommendation mechanism and its influence on consumer decisions and behaviors: A causal map approach. Expert Systems with Applications, 35(4), 1567-1574.

Lee, G., \& Lee, W. J. (2009). Psychological reactance to online recommendation services. Information \& Management, 46(8), 448-452.

Lee, T. Q., Park, Y., \& Park, Y. T. (2009). An empirical study on effectiveness of temporal information as implicit ratings. Expert Systems with Applications, 36(2), 1315-1321. 
Lee, T. Q., Park, Y., \& Park, Y. T. (2008). A time-based approach to effective recommender systems using implicit feedback. Expert systems with applications, 34(4), 3055-3062.

Li, Y., Lu, L., \& Xuefeng, L. (2005). A hybrid collaborative filtering method for multipleinterests and multiple-content recommendation in E-Commerce. Expert Systems with Applications, 28(1), 67-77.

Li, T., \& Unger, T. (2012). Willing to pay for quality personalization\&quest; Trade-off between quality and privacy. European Journal of Information Systems, 21(6), 621-642.

Li, Y. M., Wu, C. T., \& Lai, C. Y. (2013). A social recommender mechanism for ecommerce: Combining similarity, trust, and relationship. Decision Support Systems, 55(3), 740-752.

Li, Y. M., \& Yeh, Y. S. (2010). Increasing trust in mobile commerce through design aesthetics. Computers in Human Behavior, 26(4), 673-684.

Li, L., Zheng, L., Yang, F., \& Li, T. (2014). Modeling and broadening temporal user interest in personalized news recommendation. Expert Systems with Applications, 41(7), 3168-3177.

Liang, T. P., Lai, H. J., \& Ku, Y. C. (2006). Personalized content recommendation and user satisfaction: Theoretical synthesis and empirical findings. Journal of Management Information Systems, 23(3), 45-70. 
Liang, T. P., Yang, Y. F., Chen, D. N., \& Ku, Y. C. (2008). A semantic-expansion approach to personalized knowledge recommendation. Decision Support Systems, 45(3), 401-412.

Liao, S. H., Chen, C. M., Hsieh, C. L., \& Hsiao, S. C. (2009). Mining information users’ knowledge for one-to-one marketing on information appliance. Expert Systems with Applications, 36(3), 4967-4979.

Lin, C. T., Hong, W. C., Chen, Y. F., \& Dong, Y. (2010). Application of salesman-like recommendation system in 3G mobile phone online shopping decision support. Expert Systems with Applications, 37(12), 8065-8078.

Liu, D., Sarkar, S., \& Sriskandarajah, C. (2010). Resource allocation policies for personalization in content delivery sites. Information Systems Research, 21(2), 227-248.

Lu, J., Wu, D., Mao, M., Wang, W., \& Zhang, G. (2015). Recommender system application developments: A survey. Decision Support Systems, 74, 12-32.

Mandel, N., \& Johnson, E. J. (2002). When web pages influence choice: Effects of visual primes on experts and novices. Journal of Consumer Research, 29(2), 235-245.

Martin, B. A., Sherrard, M. J., \& Wentzel, D. (2005). The role of sensation seeking and need for cognition on web-site evaluations: a resource-matching perspective. Psychology and Marketing, 22(2), 109-126. 
Martín-Vicente, M. I., Gil-Solla, A., Ramos-Cabrer, M., Blanco-Fernández, Y., \& LópezNores, M. (2012). Semantic inference of user's reputation and expertise to improve collaborative recommendations. expert systems with applications, 39(9), 8248-8258.

Mathwick, C., Wagner, J., \& Unni, R. (2010). Computer-mediated customization tendency (CMCT) and the adaptive e-service experience. Journal of Retailing, 86(1), 11-21.

McCoy, M., \& Hargie, O. (2007). Effects of personalization and envelope color on response rate, speed and quality among a business population. Industrial Marketing Management, 36(6), 799-809.

Miceli, G., Ricotta, F., \& Costabile, M. (2007). Customizing customization: A conceptual framework for interactive personalization. Journal of Interactive Marketing, 21(2), 6-25.

Montgomery, A. L., \& Smith, M. D. (2009). Prospects for Personalization on the Internet. Journal of Interactive Marketing, 23(2), 130-137.

Mukherjee, A., \& Nath, P. (2007). Role of electronic trust in online retailing: A reexamination of the commitment-trust theory. European Journal of Marketing, 41(9/10), 11731202.

Murray, K. B., \& Häubl, G. (2009). Personalization without interrogation: towards more effective interactions between consumers and feature-based recommendation agents. Journal of Interactive Marketing, 23(2), 138-146. 
Parra, D., \& Brusilovsky, P. (2015). User-controllable personalization: A case study with SetFusion. International Journal of Human-Computer Studies, 78, 43-67.

Peppers, D., \& Rogers, M. (1993). The new marketing paradigm: one-to-one. American Advertising, 9(4), 93-102.

Reinecke, K., \& Bernstein, A. (2013). Knowing what a user likes: A design science approach to interfaces that automatically adapt to culture. Mis Quarterly, 37(2), 427-453.

Rose, S., Clark, M., Samouel, P., \& Hair, N. (2012). Online customer experience in eretailing: an empirical model of antecedents and outcomes. Journal of Retailing, 88(2), 308322.

Seneler, C. O., Basoglu, N., \& Daim, T. (2009). Interface feature prioritization for web services: Case of online flight reservations. Computers in Human Behavior, 25(4), 862-877.

Shen, A., \& Dwayne Ball, A. (2009). Is personalization of services always a good thing? Exploring the role of technology-mediated personalization (TMP) in service relationships. Journal of Services Marketing, 23(2), 79-91.

Shinde, S. K., \& Kulkarni, U. (2012). Hybrid personalized recommender system using centering-bunching based clustering algorithm. Expert Systems with Applications, 39(1), 1381-1387. 
Singh, N., Baack, D., \& Pereira, A. (2008). Culturally customizing websites for US Hispanic online consumers. Journal of Advertising Research, 48(2), 224-234.

Steenkamp, J. B. E., \& Geyskens, I. (2006). How country characteristics affect the perceived value of web sites. Journal of marketing, 70(3), 136-150.

Song, J. H., \& Zinkhan, G. M. (2008). Determinants of perceived web site interactivity. Journal of Marketing, 72(2), 99-113.

Sunikka, A., \& Bragge, J. (2012). Applying text-mining to personalization and customization research literature-Who, what and where?. Expert Systems with Applications, 39(11), 1004910058.

Sunikka, A., \& Bragge, J. (2008, January). What, who and where: insights into personalization. In Hawaii International Conference on System Sciences, Proceedings of the 41st Annual (pp. 283-283). IEEE.

Tam, K. Y., \& Ho, S. Y. (2006). Understanding the impact of web personalization on user information processing and decision outcomes. Mis Quarterly, 865-890.

Tam, K. Y., \& Ho, S. Y. (2005). Web personalization as a persuasion strategy: An elaboration likelihood model perspective. Information Systems Research, 16(3), 271-291.

Thirumalai, S., \& Sinha, K. K. (2013). To personalize or not to personalize online purchase interactions: Implications of self-selection by retailers. Information Systems Research, 24(3), 683-708. 
Tsai, H. T., \& Huang, H. C. (2007). Determinants of e-repurchase intentions: An integrative model of quadruple retention drivers. Information \& Management, 44(3), 231-239.

Tucker, C. E. (2014). Social networks, personalized advertising, and privacy controls. Journal of Marketing Research, 51(5), 546-562.

Tuzhilin, A. (2009) "Personalization: the state of the art and future directions” in Adomavicius, G., Gupta, A. (eds.) Business Computing: Handbooks in Information Systems, vol 3., pp. 3-43, Bingley: Emerald.

Urban, G. L., Amyx, C., \& Lorenzon, A. (2009). Online trust: state of the art, new frontiers, and research potential. Journal of Interactive Marketing, 23(2), 179-190.

Van Doorn, J., \& Hoekstra, J. C. (2013). Customization of online advertising: The role of intrusiveness. Marketing Letters, 24(4), 339-351.

Verhagen, T., van Nes, J., Feldberg, F., \& van Dolen, W. (2014). Virtual customer service agents: Using social presence and personalization to shape online service encounters. Journal of Computer-Mediated Communication, 19(3), 529-545.

Vesanen, J. (2007). What is personalization? A conceptual framework. European Journal of Marketing, 41(5/6), 409-418. 
Vesanen, J., \& Raulas, M. (2006). Building bridges for personalization: a process model for marketing. Journal of Interactive Marketing, 20(1), 5-20.

Wang, Y., \& Li, D. (2013). Testing the moderating effects of toolkits and user communities in personalization: The case of social networking service. Decision Support Systems, 55(1), 3142.

Wang, Y. J., Minor, M. S., \& Wei, J. (2011). Aesthetics and the online shopping environment: Understanding consumer responses. Journal of Retailing, 87(1), 46-58.

Wattal, S., Telang, R., \& Mukhopadhyay, T. (2009). Information personalization in a twodimensional product differentiation model. Journal of Management Information Systems, 26(2), 69-95.

Weed, D. L. (2005). Weight of evidence: a review of concept and methods. Risk Analysis, 25(6), 1545-1557.

Xu, J., Benbasat, I., \& Cenfetelli, R. T. (2014). Research Note: The Influences of Online Service Technologies and Task Complexity on Efficiency and Personalization. Information Systems Research, 25(2), 420-436.

Yang, Y. C. (2010). Web user behavioral profiling for user identification. Decision Support Systems, 49(3), 261-271. 
Zhang, J. (2011). The perils of behavior-based personalization. Marketing Science, 30(1), 170-186.

Zhang, T., Agarwal, R., \& Lucas Jr, H. C. (2011). The value of IT-enabled retailer learning: personalized product recommendations and customer store loyalty in electronic markets. MIS Quarterly-Management Information Systems, 35(4), 859.

Zhang, Y., \& Jiao, J. R. (2007). An associative classification-based recommendation system for personalization in B2C e-commerce applications. Expert Systems with Applications, 33(2), 357-367.

Zhang, J., \& Wedel, M. (2009). The effectiveness of customized promotions in online and offline stores. Journal of Marketing Research, 46(2), 190-206.

Zhang, Y., Zhang, L., \& Hossain, M. A. (2015). Adaptive 3D facial action intensity estimation and emotion recognition. Expert Systems with Applications, 42(3), 1446-1464.

Zhao, L., Lu, Y., \& Gupta, S. (2012). Disclosure intention of location-related information in location-based social network services. International Journal of Electronic Commerce, 16(4), 53-90.

Zheng, L., Li, L., Hong, W., \& Li, T. (2013). PENETRATE: Personalized news recommendation using ensemble hierarchical clustering. Expert Systems with Applications, 40(6), 2127-2136. 
Appendices

Appendix A. Complete listing of articles per journal, based on the rankings of Academic Journal Guide 2015 for marketing and IS journals

\begin{tabular}{lc}
\hline Marketing Journals & Number of target articles \\
\hline Journal of Consumer Psychology & 0 \\
\hline Journal of Consumer Research & 0 \\
\hline Journal of Marketing & 2 \\
\hline Journal of Marketing Research & 3 \\
\hline Marketing Science & 0 \\
\hline International Journal of Research in Marketing & 0 \\
\hline Journal of Retailing & 4
\end{tabular}


Journal of the Academy of Marketing Science

0

European Journal of Marketing 5

$\begin{array}{ll}\text { Industrial Marketing Management } & 0\end{array}$

$\begin{array}{ll}\text { International Marketing Review } & 0\end{array}$

$\begin{array}{ll}\text { Journal of Advertising } & 0\end{array}$

Journal of Advertising Research 1

Journal of Interactive Marketing 1

Journal of International Marketing $\quad 0$

Journal of Public Policy and Marketing 0

Marketing Letters 1

Marketing Theory 0

Psychology \& Marketing 1

Quantitative Marketing and Economics 0

\begin{tabular}{|c|c|}
\hline IS Journals & Number of target articles \\
\hline Information Systems Research & 6 \\
\hline MIS Quarterly & 7 \\
\hline Journal of Management Information Systems & 3 \\
\hline Journal of the Association of Information Systems & 0 \\
\hline Computers in Human Behavior & 6 \\
\hline Decision Support Systems & 9 \\
\hline European Journal of Information Systems & 1 \\
\hline Expert Systems with Applications & 31 \\
\hline Government Information Quarterly & 0 \\
\hline Information \& Management & 3 \\
\hline Information and Organization & 0 \\
\hline Information Society & 0 \\
\hline Information Systems Frontiers & 1 \\
\hline Information Systems Journal & 0 \\
\hline Information Technology and People & 0 \\
\hline International Journal of Electronic Commerce & 3 \\
\hline International Journal of Human-Computer Studies & 2 \\
\hline Journal of Computer Mediated Communication & 2 \\
\hline Journal of Information Technology & 0 \\
\hline
\end{tabular}




\section{Appendix B. Complete article listing of the dataset}

\begin{tabular}{|c|c|c|c|c|c|}
\hline No. & Citation & Year & Method & Category & Journal \\
\hline 1 & Aguirre et al. & 2015 & Survey & PR; TR & Journal of Retailing \\
\hline 2 & Capuano et al. & 2015 & Experiment & PE; DCP & Computers in Human Behavior \\
\hline 3 & Che et al. & 2015 & Survey & LO & Information \& Management \\
\hline 4 & Colace et al. & 2015 & Case study & DCP & Computers in Human Behavior \\
\hline 5 & Lu et al. & 2015 & Literature review & TH & Decision Support Systems \\
\hline 6 & Parra \& Brusilovsky & 2015 & Experiment & DI & Int. J. of Hum.-Comp. Studies \\
\hline 7 & Gedikli, Jannach \& Ge & 2014 & Experiment & $\mathrm{CO}$ & Int. J. of Hum.-Comp. Studies \\
\hline 8 & Ho \& Bodoff & 2014 & Field experiment & $\mathrm{PD} ; \mathrm{TH}$ & MIS Quarterly \\
\hline 9 & Johar, Mokherjee \& Sarkar & 2014 & Conceptual & $\mathrm{TH}$ & Information Systems Research \\
\hline 10 & Li et al. & 2014 & Experiment & TI; RS & Expert Systems with Applications \\
\hline 11 & Tucker & 2014 & Field experiment & PR & Journal of Marketing Research \\
\hline 12 & Verhagen et al. & 2014 & Experiment & $\mathrm{CE} ; \mathrm{SP}$ & J. of Comp. Mediated Comm. \\
\hline 13 & Xu, Benbasat \& Cenfetelli & 2014 & Experiment & PrR & Information Systems Research \\
\hline 14 & Al-Shamri & 2014 & Experiment & $\mathrm{TH}$ & Expert Systems with Applications \\
\hline 15 & Chau et al. & 2013 & Field experiment & TR & Decision Support Systems \\
\hline 16 & Kang \& Sundar & 2013 & Experiment & IP & Computers in Human Behavior \\
\hline 17 & Lambrecht \& Tucker & 2013 & Field experiment & $\mathrm{DR} / \mathrm{CP}$ & Journal of Marketing Research \\
\hline 18 & Lee, Choi \& Suh & 2013 & Experiment & RS & Expert Systems with Applications \\
\hline 19 & Li, Wu\& Lai & 2013 & Experiment & RS & Decision Support Systems \\
\hline 20 & Reinecke \& Bernstein & 2013 & Experiment & CU; DI & MIS Quarterly \\
\hline 21 & Thirumalai \& Sinha & 2013 & Counterfactual analysis & LO & Information Systems Research \\
\hline 22 & van Doorn \& Hoekstra & 2013 & Experiment & PR; PI; DR/CP & Marketing Letters \\
\hline 23 & Wang \& Li & 2013 & Survey & SM & Decision Support Systems \\
\hline 24 & Zheng et al. & 2013 & Experiment & RS & Expert Systems with Applications \\
\hline 25 & Hong \& Kim & 2012 & Survey & TR; PI; DCP & Expert Systems with Applications \\
\hline 26 & Hong, Li \& Li & 2012 & Experiment & TI; DCP & Expert Systems with Applications \\
\hline 27 & Li \& Unger & 2012 & Experiment & PR & Europ. J. of Information Systems \\
\hline 28 & Lucas, Segrera \& Moreno & 2012 & Case study & $\mathrm{TH}$ & Expert Systems with Applications \\
\hline 29 & Martín-Vicente et al. & 2012 & Conceptual & TR; DCP; TH & Expert Systems with Applications \\
\hline 30 & Rose et al. & 2012 & Survey & $\mathrm{CE} ; \mathrm{TH}$ & Journal of Retailing \\
\hline 31 & Shinde \& Kulkarni & 2012 & Experiment & RS & Expert Systems with Applications \\
\hline 32 & Sunikka \& Bragge & 2012 & Literature review & $\mathrm{TH}$ & Expert Systems with Applications \\
\hline 33 & Zhao, Lu \& Gupta & 2012 & Conceptual & PR; TH & Int. J. of Electronic Commerce \\
\hline
\end{tabular}




\begin{tabular}{|c|c|c|c|c|c|}
\hline 34 & Choi, Lee \& Kim & 2011 & Experiment & SP & Int. J. of Electronic Commerce \\
\hline 35 & Ho, Bodoff \& Tam & 2011 & Field experiment & $\mathrm{TI}$ & Information Systems Research \\
\hline 36 & Lee, Ahn \& Bang & 2011 & Conceptual & PR; TH & MIS Quarterly \\
\hline 37 & Wang, Minor \& Wei & 2011 & Experiment & DI; TH & Journal of Retailing \\
\hline 38 & Zhang, Agarwal \& Lucas & 2011 & Experiment & $\mathrm{LO}$ & MIS Quarterly \\
\hline 39 & Ahn, Kang \& Lee & 2010 & Experiment & DCP & Expert Systems with Applications \\
\hline 40 & Blanco-Fernández et al. & 2010 & Experiment & TI; DCP & Expert Systems with Applications \\
\hline 41 & Chen et al. & 2010 & Experiment & $\mathrm{CP} ; \mathrm{RS}$ & Expert Systems with Applications \\
\hline 42 & Chou et al. & 2010 & Experiment & P-SK; DCP & Expert Systems with Applications \\
\hline 43 & Gao, Liu \& Wu & 2010 & Literature review & $\mathrm{TH}$ & Information Systems Frontiers \\
\hline 44 & Ha, Muthaly \& Akamavi & 2010 & Survey & PeI; CU; SA; LO & European Journal of Marketing \\
\hline 45 & Jalalali et al. & 2010 & Experiment & RS & Expert Systems with Applications \\
\hline 46 & Jiang, Shan \& Liu & 2010 & Experiment & RS & Decision Support Systems \\
\hline 47 & Li \& Yeh & 2010 & Survey & TR; DI & Computers in Human Behavior \\
\hline 48 & Lin et al. & 2010 & Experiment & RS & Expert Systems with Applications \\
\hline 49 & Liu, Sarkar \& Srikandarajah & 2010 & Experiment & PrR & Information Systems Research \\
\hline 50 & Mathwick, Wagner \& Unni & 2010 & Interview/Survey & $\mathrm{CP}$ & Journal of Retailing \\
\hline 51 & Yang & 2010 & Experiment & DCP & Decision Support Systems \\
\hline 52 & Albadvi \& Shahbazi & 2009 & Experiment & $\mathrm{CP} ; \mathrm{RS}$ & Expert Systems with Applications \\
\hline 53 & Chang et al. & 2009 & Survey & DCP & Expert Systems with Applications \\
\hline 54 & Gevorgyan \& Manucharova & 2009 & Survey/Content analysis & CU; DI & J. of Comp. Mediated Comm. \\
\hline 55 & Herrington \& Weaven & 2009 & Survey & SA & European Journal of Marketing \\
\hline 56 & Kim, Kim \& Kandampully & 2009 & Survey & SA & European Journal of Marketing \\
\hline 57 & Lee \& Lee & 2009 & Experiment & $\mathrm{AD}$ & Information \& Management \\
\hline 58 & Lee, Park \& Park & 2009 & Experiment & $\mathrm{TI}$ & Expert Systems with Applications \\
\hline 59 & Liao et al. & 2009 & Survey & DCP; TH & Expert Systems with Applications \\
\hline 60 & Seneler, Basoglu \& Daim & 2009 & Experiment & DI & Computers in Human Behavior \\
\hline 61 & $\begin{array}{l}\text { Wattal, Telang \& } \\
\text { Mukhopadhyay }\end{array}$ & 2009 & Conceptual & $\mathrm{CP} ; \mathrm{TH}$ & J. of Mgt. Information Systems \\
\hline 62 & Weng, Lin \& Chen & 2009 & Experiment & $\mathrm{TH}$ & Expert Systems with Applications \\
\hline 63 & Zhang \& Wedel & 2009 & Experiment & $\mathrm{DR} / \mathrm{CP}$ & Journal of Marketing Research \\
\hline 64 & Chang \& Chen & 2008 & Survey & LO; DI & Computers in Human Behavior \\
\hline 65 & Da Silwa \& Alwi & 2008 & Survey & BI & European Journal of Marketing \\
\hline 66 & Huang et al. & 2008 & Experiment & DCP & Expert Systems with Applications \\
\hline 67 & $\begin{array}{l}\text { Lazcorreta, Botella \& } \\
\text { Fernández-Cabalero }\end{array}$ & 2008 & Conceptual & DCP & Expert Systems with Applications \\
\hline 68 & Lee \& Kwon & 2008 & Experiment & PI; IP; RS & Expert Systems with Applications \\
\hline 69 & Lee, Park \& Park & 2008 & Experiment & $\mathrm{TI} ; \mathrm{RS}$ & Expert Systems with Applications \\
\hline 70 & Liang et al. & 2008 & Experiment & RS & Decision Support Systems \\
\hline
\end{tabular}




\begin{tabular}{|c|c|c|c|c|c|}
\hline 71 & Singh et al. & 2008 & Survey/Focus group & CU & Journal of Advertising Research \\
\hline 72 & Song \& Zinkham & 2008 & Experiment & PeI & Journal of Marketing \\
\hline 73 & Cao \& Li & 2007 & Experiment & RS & Expert Systems with Applications \\
\hline 74 & Chellappa \& Shivendu & 2007 & Conceptual & PR & J. of Mgt. Information Systems \\
\hline 75 & Miceli, Ricotta \& Costabile & 2007 & Conceptual/Survey & $\mathrm{TH}$ & Journal of Interactive Marketing \\
\hline 76 & Mukherjee \& Nath & 2007 & Survey & TR; LO & European Journal of Marketing \\
\hline 77 & Tsai \& Huang & 2007 & Survey & LO & Information \& Management \\
\hline 78 & Zhang \& Jiao & 2007 & Experiment & RS & Expert Systems with Applications \\
\hline 79 & Awad \& Krishnan & 2006 & Survey & PR & MIS Quarterly \\
\hline 80 & Chang, Changchien \& Huang & 2006 & Experiment & P-SK; DCP & Expert Systems with Applications \\
\hline 81 & Devarai, Fan \& Kohli & 2006 & Survey & $\mathrm{CP} ; \mathrm{SA}$ & Decision Support Systems \\
\hline 82 & Fan, Gordon \& Pathak & 2006 & Experiment & DCP & Decision Support Systems \\
\hline 83 & Komiak \& Benbasat & 2006 & Experiment & TR; AD & MIS Quarterly \\
\hline 84 & Liang, Lai \& Ku & 2006 & Experiment & SA; TH & J. of Mgt. Information Systems \\
\hline 85 & Steenkamp \& Geyskens & 2006 & Survey & $\mathrm{CU}$ & Journal of Marketing \\
\hline 86 & Tam \& Ho & 2006 & Field experiment & IP; TH & MIS Quarterly \\
\hline 87 & Huang & 2005 & Experiment & RS & Expert Systems with Applications \\
\hline 88 & Koch \& Möslein & 2005 & Conceptual & PR & Int. J. of Electronic Commerce \\
\hline 89 & Li, Lu \& Xuefeng & 2005 & Experiment & RS & Expert Systems with Applications \\
\hline 90 & Martin, Sherrard \& Wentzel & 2005 & Experiment & PE; DI & Psychology \& Marketing \\
\hline 91 & Tam \& Ho & 2005 & Field experiment & PD; IP & Information Systems Research \\
\hline
\end{tabular}

$\mathrm{AD}=$ customer adoption, $\mathrm{BI}=$ brand image, $\mathrm{CE}=$ customer experience, $\mathrm{CO}=$ content design, $\mathrm{CP}=$ customer preferences, $\mathrm{CU}=$ cultural effects, DCP = data collection and processing, DI = design/interface, DR/CP = dynamic retargeting/customized promotions, IP = information processing, $\mathrm{LO}=$ loyalty, $\mathrm{PD}=$ personal disposition, $\mathrm{PE}=$ personality, $\mathrm{PeI}=$ perceived interactivity, $\mathrm{PI}=$ purchase intention, $\mathrm{PR}=$ privacy $\mathrm{PrR}=$ processing resources, $\mathrm{P}-\mathrm{SK}=$ product-specific knowledge, $\mathrm{RS}=$ recommender systems, $\mathrm{SA}=$ satisfaction, $\mathrm{SM}=$ support mechanisms, $\mathrm{SP}=$ social presence, $\mathrm{TH}=$ theoretical foundations, $\mathrm{TI}=$ timing, $\mathrm{TR}=$ trust

\section{List of figures}

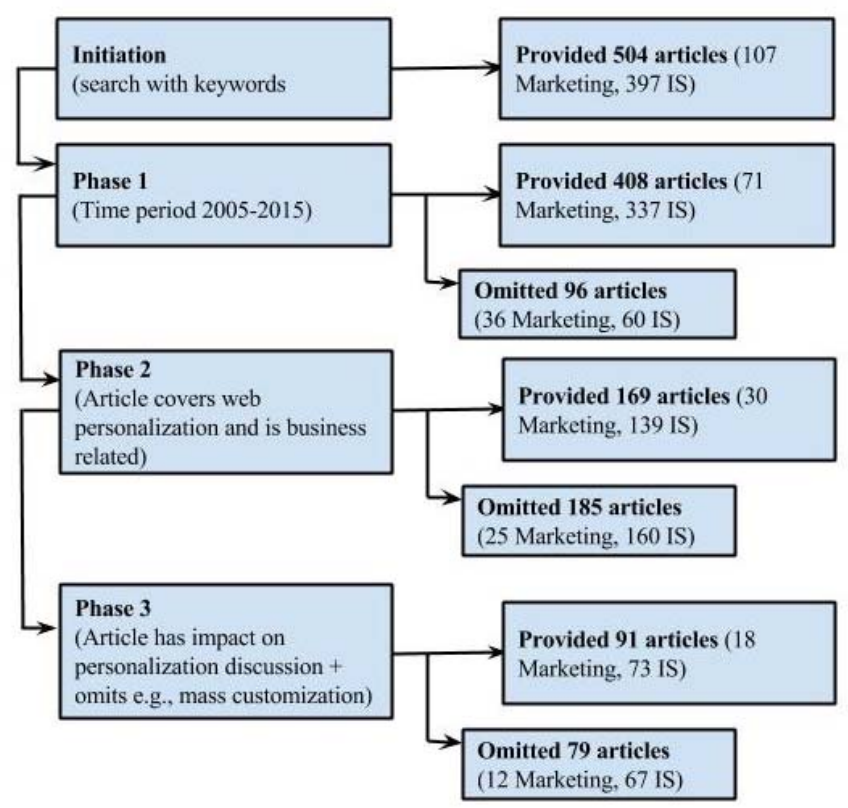


Figure 1. Summary of the systematic review process

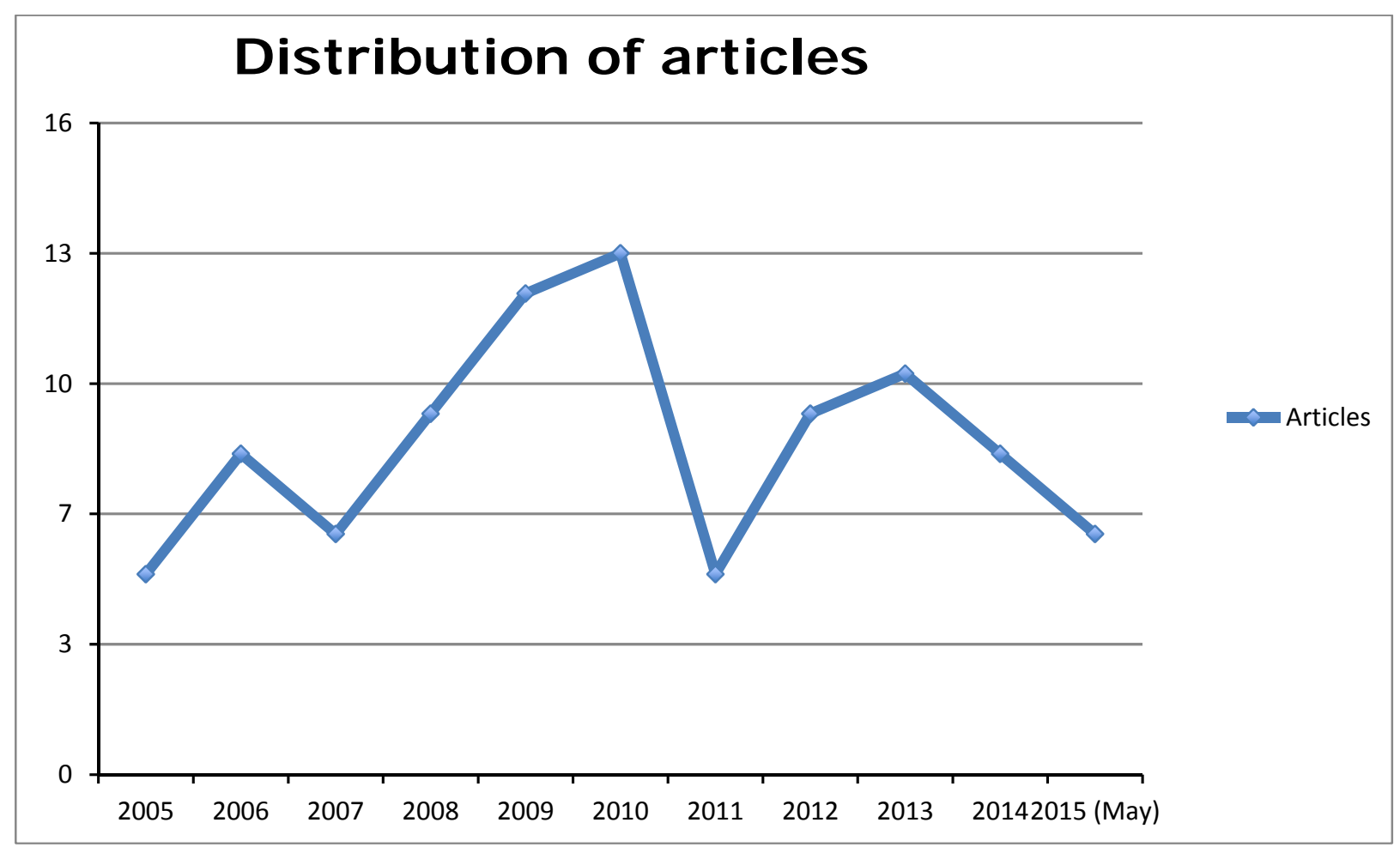

Figure 2. Annual distribution of articles in the dataset List of tables

Table 1. Top six contributing journals in the dataset

\begin{tabular}{lr} 
Journal & Articles \\
\hline Expert Systems with Applications & 31 \\
\hline Decision Support Systems & 9 \\
MIS Quarterly & 7 \\
\hline Information Systems Research & 6 \\
Computers in Human Behavior & 6 \\
European Journal of Marketing & 5 \\
\hline
\end{tabular}

Table 2. Summary of selected research on user-centric aspects

\begin{tabular}{ll}
\hline User-centric aspects & Reference \\
\hline Perceived interactivity & Ha, Muthaly \& Akavami (2010); Song \& Zinkham (2008)
\end{tabular}


Cultural effects on consumer behavior

\begin{tabular}{l} 
Privacy \\
\hline Customer experience \\
Customer preferences \\
\hline Brand image \\
Customer trust \\
Customer satisfaction \\
\hline $\begin{array}{l}\text { Consumer } \\
\text { loyalty/commitment/revisit } \\
\text { intention / repurchase } \\
\text { intention }\end{array}$
\end{tabular}

Purchase intention

Timing

Blanco-Fernández et al. (2010); Ho, Bodoff \& Tam (2011); Hong, Li \& Li (2012); Lee, Park \& Park (2009); Lee, Park \& Park (2008); Li et al. (2014)

Personal disposition /

Ho \& Bodoff (2014); Tam \& Ho (2005)

customer attitude / motivation

Gevorgyan \& Manucharova (2009); Ha, Muthaly \& Akavami (2010); Steenkamp \& Geyskens (2006); Reinecke \& Bernstein (2013); Singh et al. (2008)

Aguirre et al. (2015); Awad \& Krishnan (2006); Chellappa \& Shivendu (2007); Koch \& Möslein (2005); Lee, Ahn \& Bang (2011); Li \& Unger (2012); Tucker (2014); Van Doorn \& Hoekstra (2013); Zhao, Lu \& Gupta (2012)

Rose et al. (2012); Verhagen, van Nes, Feldberg \& van Dolen (2014)

Albadvi \& Shahbazi (2009); Chen et al. (2010); Devaraj, Fan \& Kohli (2006); Mathwick, Wagner \& Unni (2010); Wattal, Telang \& Mukhopadhyay (2009)

Da Silva \& Alwi (2008)

Aguirre et al. (2015); Chau et al. (2013); Hong \& Kim (2012); Komiak \& Benbasat (2006); Li \& Yeh (2010); Martín-Vicente et al. (2012); Mukherjee \& Nath (2007)

Devaraj, Fan \& Kohli (2006); Ha, Muthaly \& Akavami (2010); Herrington \& Weaven (2009); Kim, Kim \& Kandampully 2009; Liang, Lai \& Ku (2006)

Zhang, Agarwal \& Lucas (2011); Che et al. (2015); Chang \& Chen (2008); Ha, Muthaly \& Akavami (2010); Mukherjee \& Nath (2007); Thirumalai \& Sinha 2013; Tsai \& Huang (2007)

Hong \& Kim (2012); Lee \& Kwon (2008); Van Doorn \& Hoekstra (2013)

Information processing /

Kang \& Sundar (2013); Lee \& Kwon (2008); Tam \& Ho (2006)

decision making

Customer personality

Capuano et al. (2015); Martin, Sherrard \& Wentzel (2005)

Product-specific knowledge Chang, Changchien \& Huang (2006); Chou et al. (2010)

Customer adoption

Komiak \& Benbasat (2006); Lee \& Lee (2009)

Social presence

Choi, Lee \& Kim (2011); Verhagen et al. (2014)

Table 3. Summary of selected literature on web personalization implementation

\section{Implementation}

Reference 


\section{Dynamic retargeting / Lambrecht \& Tucker (2013); Van Doorn \& Hoekstra (2013); Zhang \& customized promotions Wedel (2009)}

Design/interface Chang \& Chen (2008); Gevorgyan \& Manucharova (2009); Li \& Yeh (2010); Martin, Sherrard \& Wentzel (2005); Parra \& Brusilovsky (2015); Reinecke \& Bernstein (2013); Seneler, Basoglu \& Daim (2009); Wang, Minor \& Wei (2011)

\begin{tabular}{cl}
\hline Processing resources & Liu, Sarkar \& Sriskandarajah (2010); Xu, Benbasat \& Cenfetelli (2014) \\
Recommender systems & $\begin{array}{l}\text { Albadvi \& Shahbazi (2009); Cao \& Li (2007); Chen et al. (2010); Hung } \\
\text { (2005); Jalali et al. (2010); Jiang, Shang \& Liu (2010); Lee, Choi \& Suh }\end{array}$ \\
& (2013); Lee \& Huang (2011); Lee \& Kwon (2008); Lee, Park \& Park \\
& (2008); Li et al. (2014); Li, Lu \& Xuefeng (2005); Li, Wu \& Lai (2013); \\
& Liang et al. (2008); Lin et al. (2010); Shinde \& Kulkarni (2012); Zhang \& \\
& Jiao (2007); Zheng et al. (2013)
\end{tabular}

